\title{
AN APPRAISAL OF THE USE OF GESTALT PRINCIPLES IN LOGOGRAPHIC COMMUNICATION AMONG SELECT GRAPHIC ARTISTS IN A NIGERIAN URBAN CITY
}

\author{
Allen Nnanwuba Adum, PhD \\ Department of Mass Communication \\ Nnamdi Azikiwe University, Awka \\ an.adum@unizik.edu.ng \\ Charles Okika \\ Department of Mass Communication \\ Nnamdi Azikiwe University, Awka \\ Kobimdi Umeh \\ Department of Mass Communication \\ Nnamdi Azikiwe University, Awka \\ Nnaemeka Iwuchukwu \\ Department of Mass Communication \\ Nnamdi Azikiwe University, Awka
}

\begin{abstract}
This paper appraised the use of Gestalt design principles in logo graphics communication, in recognition of the role logos play in image-making and the identity of companies, businesses and brands. When a new business is planned, the need to find a logo designer who can come up with a creative and exclusive business logo arises. Elegance, creativity and excellence of design help business logos to give unlimited boost to organizations. Against this backdrop, the purpose of this study was to ascertain the use of the Gestalt principles by logographic artists in select business areas in Awka urban. We asked, how aware are logographic artists of Gestalt principles and whether they applied these principles in their logo designs. The Gestalt principles of design were employed as the yardstick for this study. Data were collected from a selected number of logographic artists in Awka Urban, Anambra state, using IDIs (Indepth interviews), from the business areas in town. The major findings of this study suggested that more than twothird of the artists studied were aware of the Gestalt principles but were not so keen in applying them to their designs due to the dictates of client's choice and satisfaction
\end{abstract}

Keywords: Gestalt principles, logo designs, logographic artists, logo graphics communication

\section{INTRODUCTION}

The various principles of Gestalt, the organization of perceptual scenes, came up in the 1920s. Max Wertheimer, a German psychologist distinguished the various principles of Gestalt, some of which, includes the principle of proximity, the principle of similarity, the principle of continuity, the principle of closure and the figure-ground principle. As a result of these principles, Gestalt psychology became popular in Germany. Max Wertheimer and his German associates Wolfgang Kohler and Kurt Koffka had ever since been held as the founders of Gestalt psychology (Hergenhahn, 2009). 
Volume 1 Number 1 Maiden Issue

\section{GESTALT PRINCIPLES}

Gestalt psychology was first proposed by German psychologists in the 1920s. It was used to explain how people organized visual information. Gestalt psychology was defined as the investigation of conscious experience through introspection and see things in meaning, whole intact configurations (Bradley, 2014). The term Gestalt is a psychology word. It refers to a "unified whole". It is based on the theories of visual perception developed by German psychologists in the 1920s. These theories picture how people would organize visual elements into groups or unified wholes when certain principles are applied (Szwemin, 2015). These principles are:

Similarity: When objects look similar to one another, Similarity occurs. These objects are often perceived as a group or pattern.

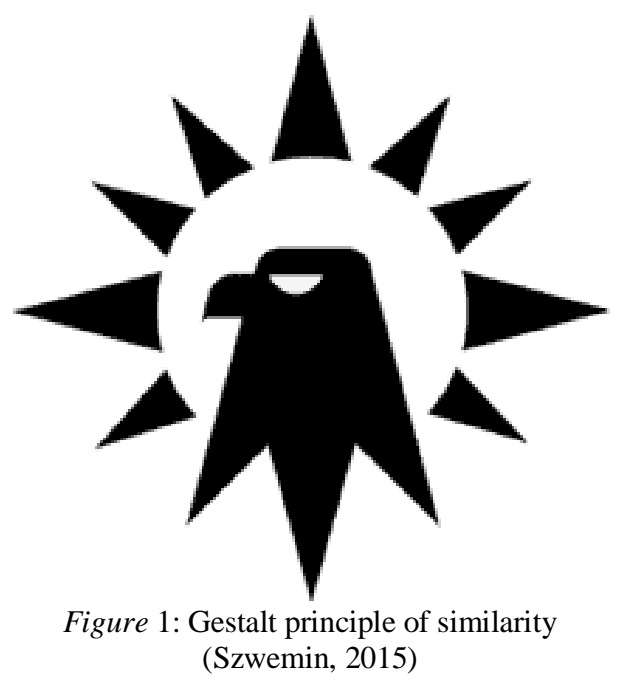

The example in Fig. 1, containing 11 distinct objects, appears as as single unit because all of the shapes appear similar. Unity occurs because the triangular shapes at the bottom of the eagle symbol look similar to the shapes that form the sunburst.

When similarity occurs, an object can be emphasized if it is dissimilar to the others. This is called anomaly.

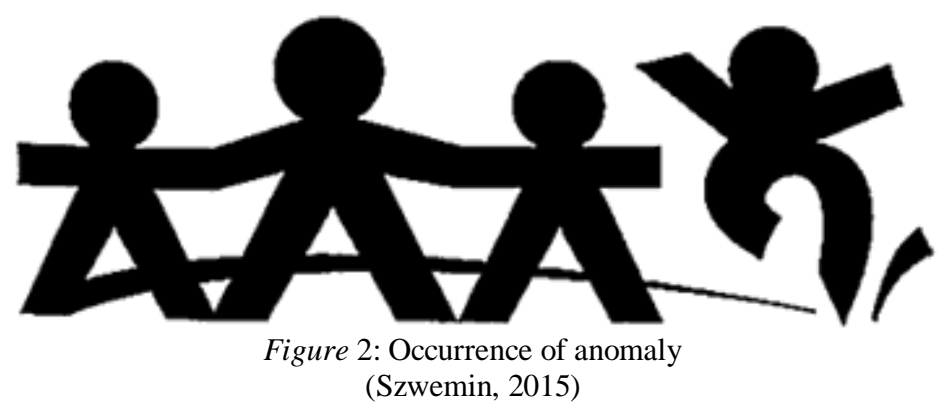

In Fig. 2, the figure on the far right forms a focal point because it is dissimilar to the other shapes.

Continuation: When the eye is compelled to move through one object and continue to another object, continuation occurs. 


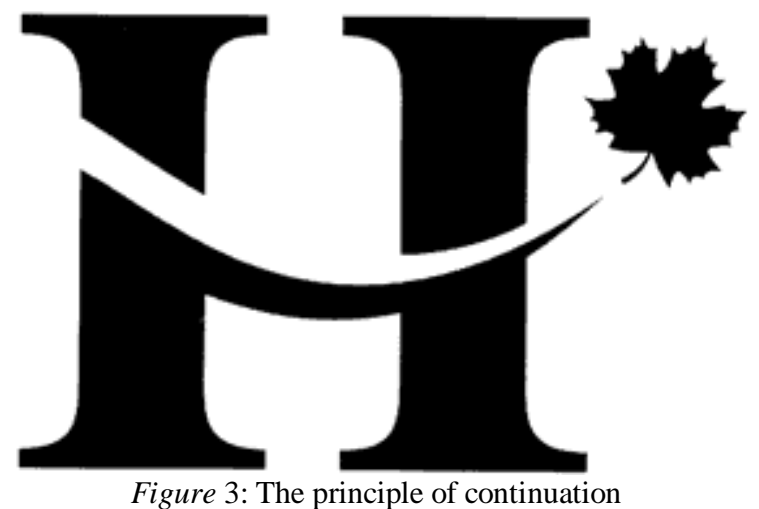

(Szwemin, 2015)

Continuation occurs in the example in Fig. 3, because the viewer's eye will naturally follow a line or curve. The eye is led directly to the maple leaf by the smooth flowing crossbar of the "H".

Closure: When an object is incomplete or a space is not completely enclosed, Closure occurs.

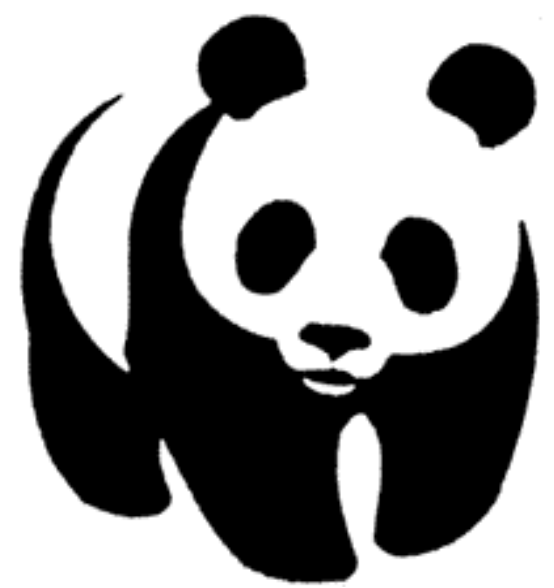

Figure 4: The principle of Closure (Szwemin, 2015)

Although the panda in Fig. 4 is not complete, enough is present for the eye to complete the shape. Closure occurs when the viewer's perception completes a shape.

Proximity: When elements are placed close together Proximity occurs. Such elements tend to be perceived as a group. 


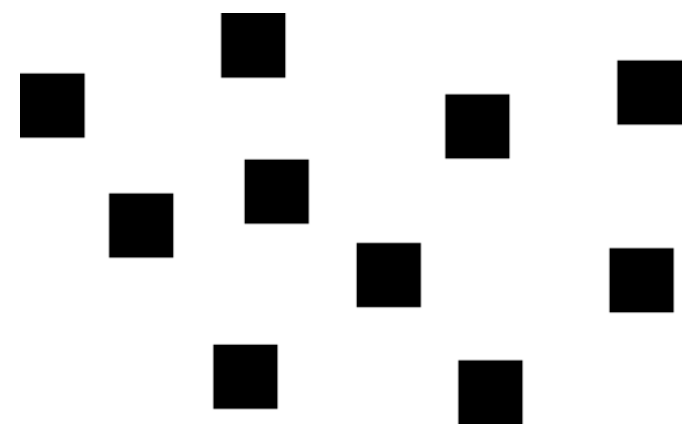

Figure 5: The principle of Proximity

(Szwemin, 2015)

The nine squares in Figure 5 are placed without proximity. They are, therefore, perceived as separate shapes.

Figure and Ground: The eye differentiates an object from its surrounding area. Aform, silhouette, or shape is naturrally perceived as figure(object), while the surrounding area is perceived as ground(background). Balancing figure and ground can make the perceived image clearer. Using unusual figure/ground relationships can add interest and sublety to an image.

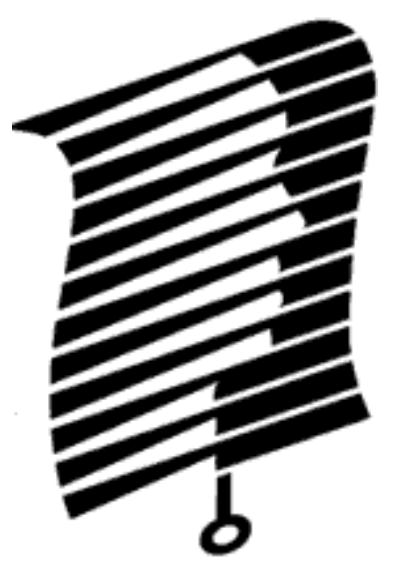

Figure 6: The principle of

Figure and Ground (Szwemin, 2015)

\section{WELL-KNOWN LOGO EVOLUTION}

Logo design is an important area of graphic design, and one of the most difficult to perfect. The logo (ideogram) is the image embodying an organization. Because logos are meant to represent companies' brands or corporate identities and foster their immediate customer recognition, it is counter-productive to frequently redesign logos (Carrie, 2020).

The evolution of logo designing could be traced back to the Ancient Greece, when the rulers and their dynasties used to use cipher as a monogram in their coins. However, the modern logo designing dates back to the early days of the Renaissance, around the 13th Century. Goldsmiths, masons, paper makers, and potters, were among the first trades people 
NNAMDI AZIKIWE UNIVERSITY Journal OF COMMUNICATION AND MEDIA STUDIES

Volume 1 Number 1 Maiden Issue

to use marks-pressings into gold, chiselled symbols, watermarks on paper, and simple thumbprints on pottery (Mertes, 2020).

Today there are many corporations, products, brands, services, agencies and other entities using logos, which have undergone some evolution. The following are a few examples of these logos:

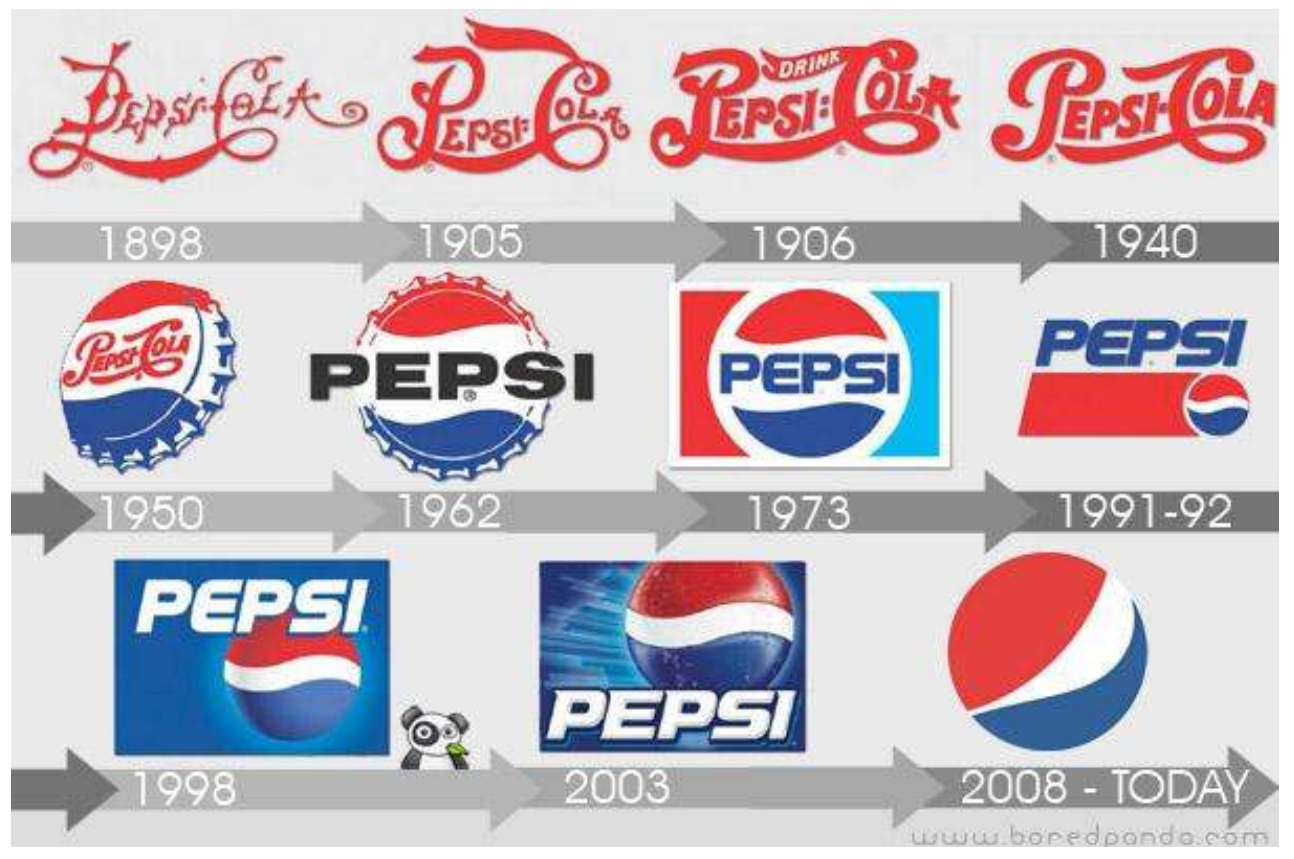

Figure 7: Evolution of Pepsi logo (Source: Pinterest)

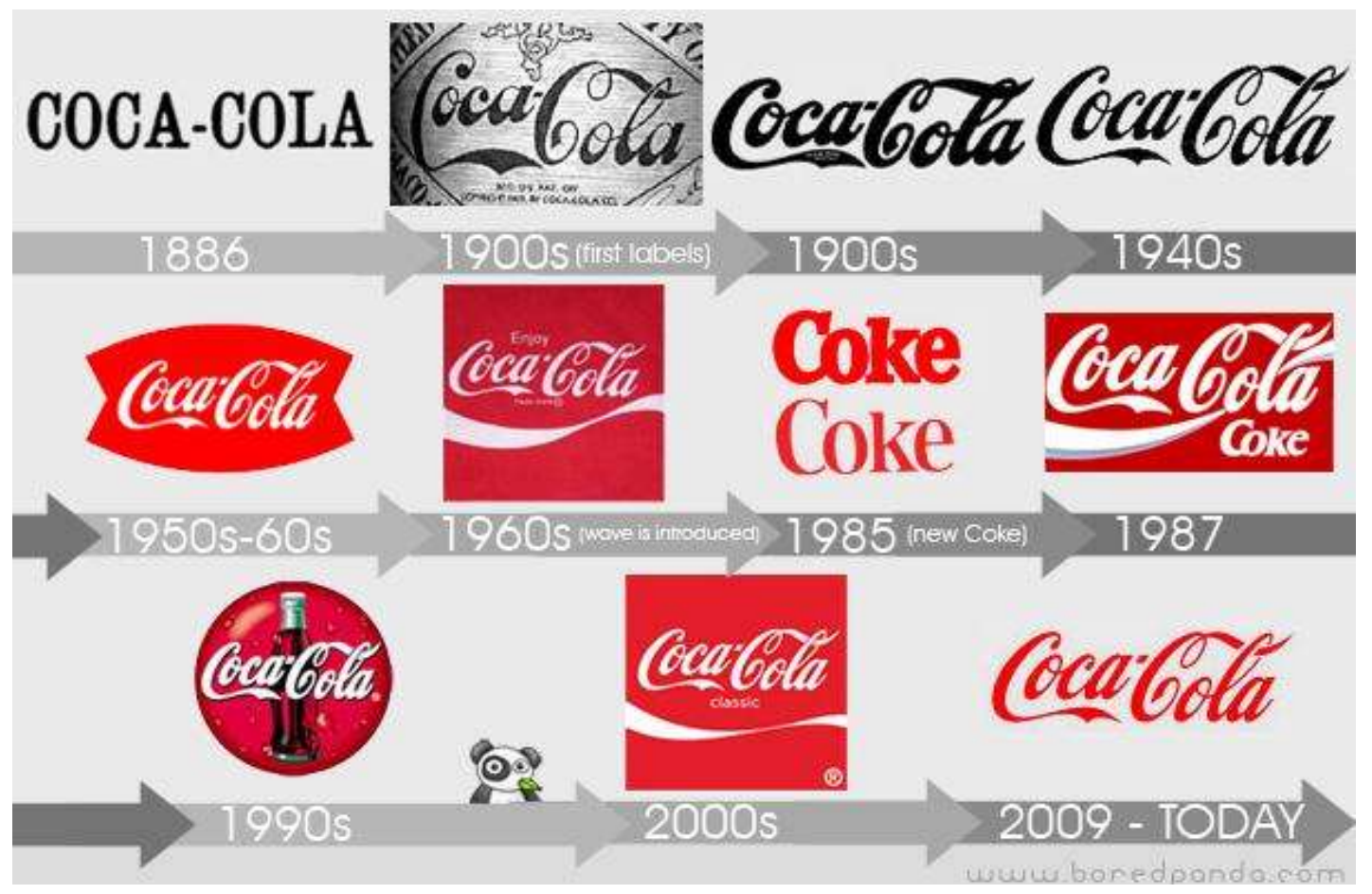

Figure 8: Evolution of Coca-Cola logo (Source: Pinterest) 
NNAMDI AZIKIWE UNIVERSITY Journal of COMMUNICATTON AND MEDLA STUDIES

Volume 1 Number 1 Maiden Issue

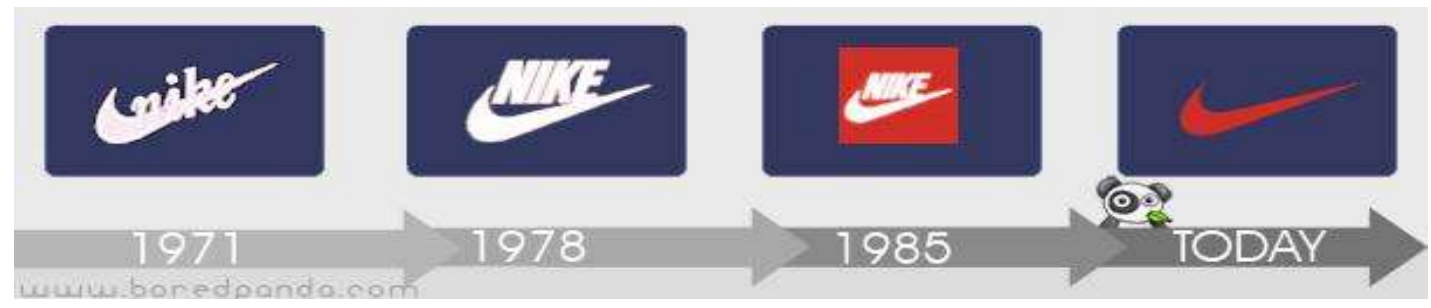

Figure 9: Evolution of Nike logo (Source: Pinterest)

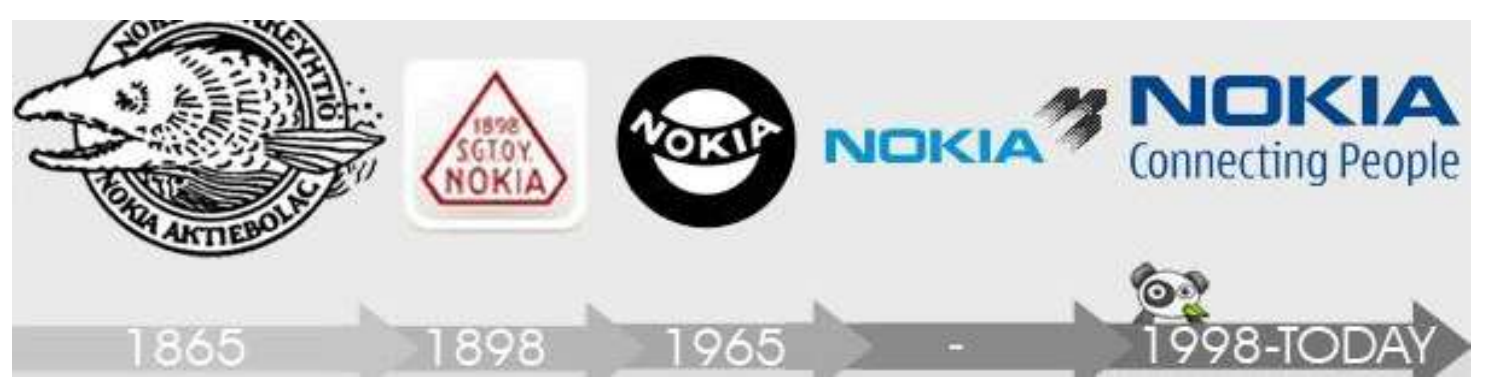

Figure 10: Evolution of Nokia logo (Source: Pinterest)

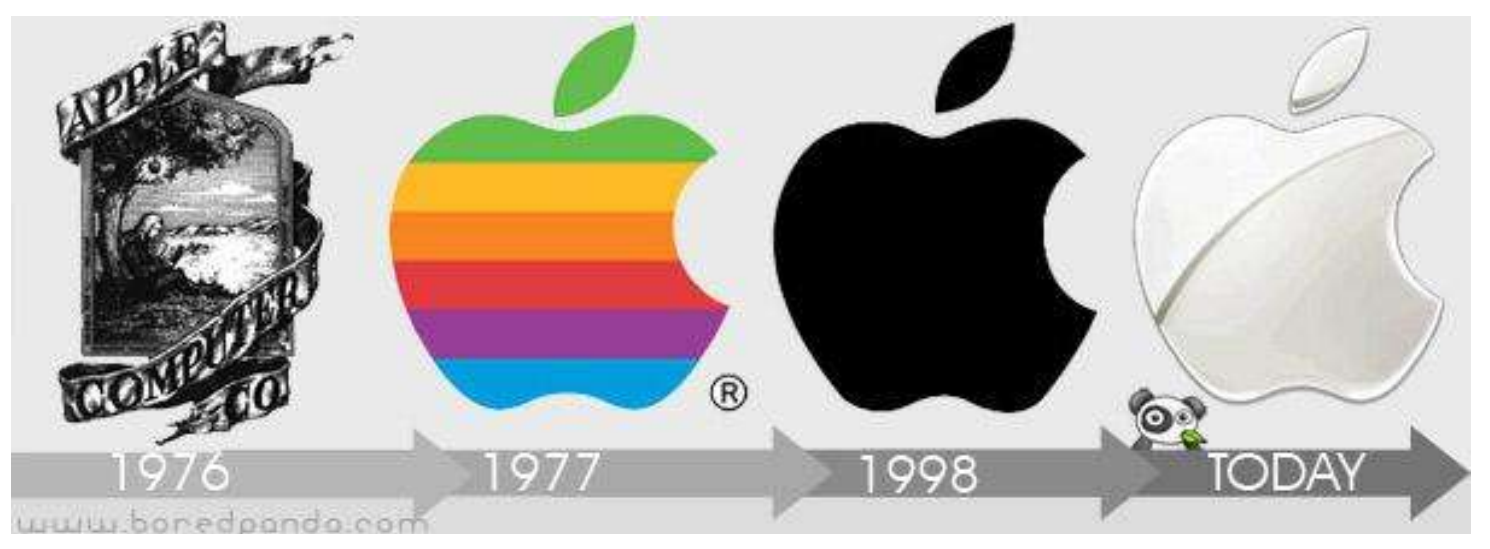

Figure 10: Evolution of Apple logo (Source: Pinterest)

\section{Google Google! Google 1998 (sept-0.t) 1998 (Nov) 1999-1ODAY}

Figure 11: Evolution of Google logo (Source: Pinterest) 


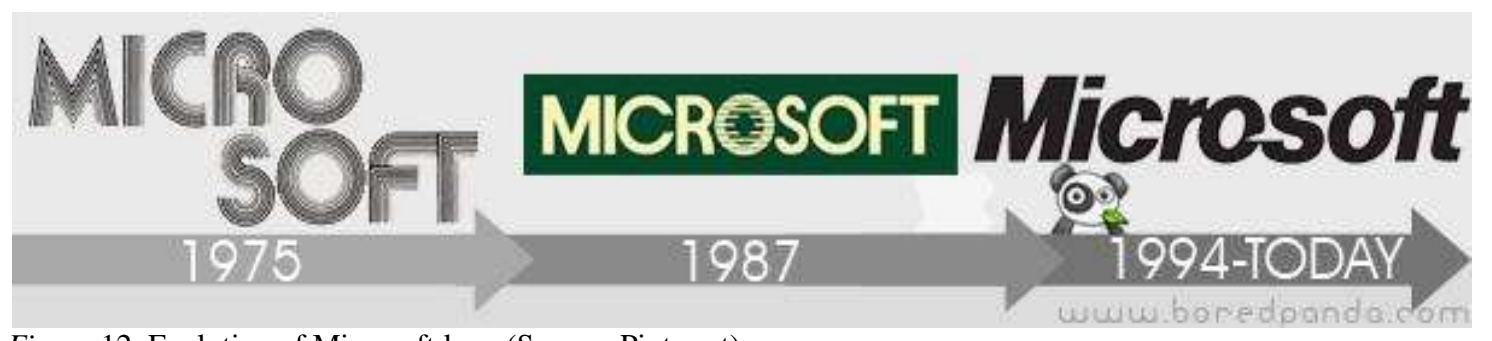

Figure 12: Evolution of Microsoft logo (Source: Pinterest)

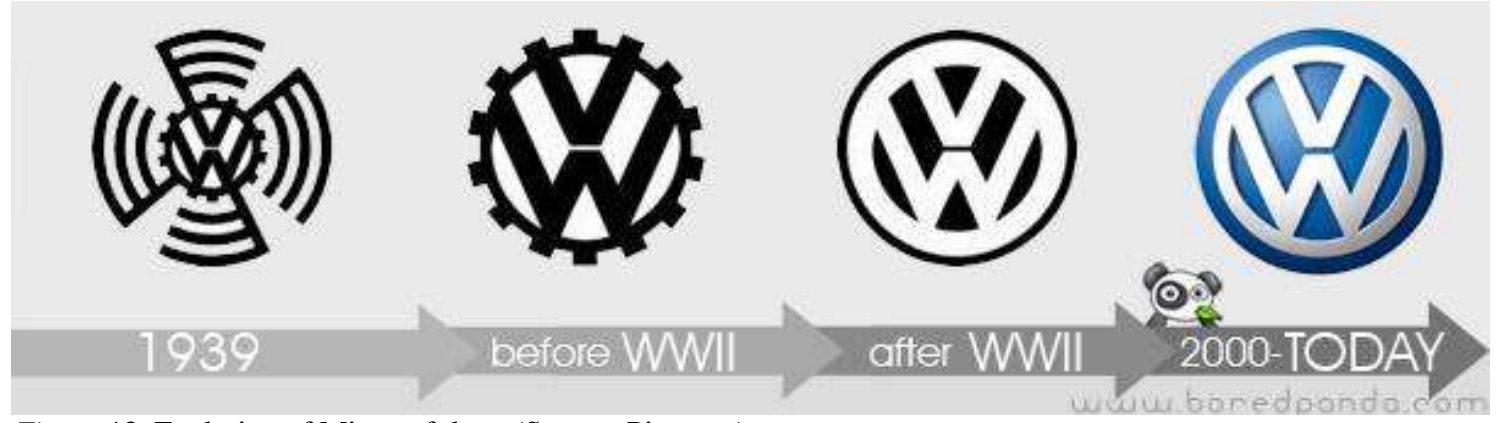

Figure.13: Evolution of Microsoft logo (Source: Pinterest)

\section{REFLECTING THE GESTALT PRINCIPLES IN LOGO DESIGNS}

The human brain is subconsciously guided by Gestalt Principles while observing the physical world. Logo designers can use these to make business logos memorable. A few practical applications for each of these Gestalt principles, in the design of the logos of well known companies, shows how visually stimulating logos that are based on these principles could be.

\section{Similarity:}

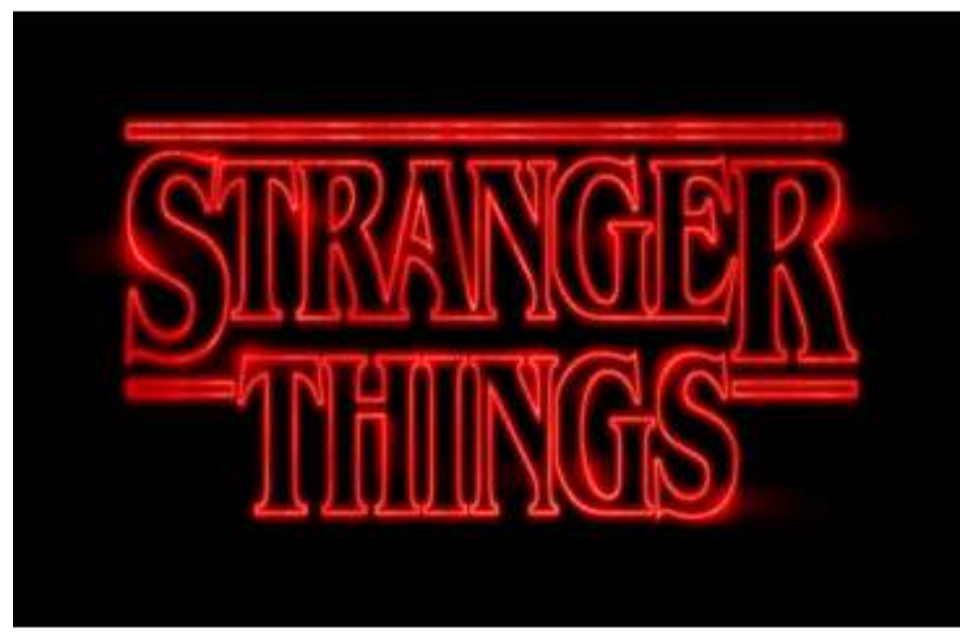

Figure. 14: Netflix brand logo (LaRosa, 2019)

The example in Fig. 14 is the iconic typography style from Netflix's "Stranger Things". There is a sense of cohesion throughout this brand; everything from the colours to the shapes that were used. 


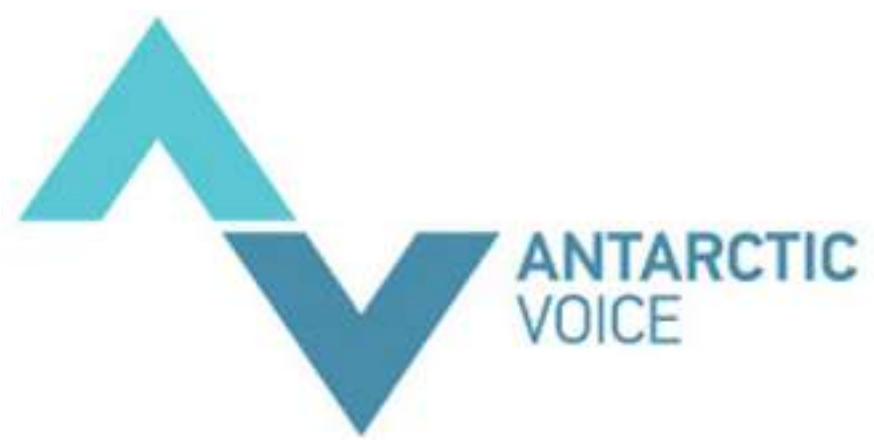

Figure 15: Antarctic Voice logo (Source: Austronaut design)

Similarity suggests cohesion to the human eye but anomaly, as depicted in Fig. 15, can be inspiring. The two symmetric pikes represent both an iceberg and a vice equalizer.

\section{Continuation}

Continuation, here, implies natural flow; just as rivers flow. Rivers have continuity; they ebb and flow yet every twist and turn feels cohesive. This sort of flow in a logo leads the eye along, in a way that demands the brain's attention. This principle comes to life when the brain sees a logo as a unit rather than a sum of letters or parts.

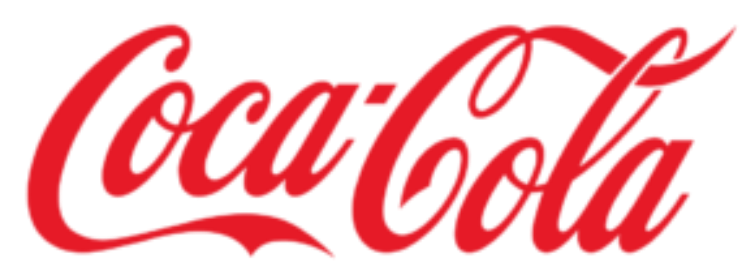

Figure 16: Coca-Cola logo (LaRosa, 2019)

One good example of continuation is Coca-Cola; the brand that has affected humans around the world. As depicted in Fig. 16, even though "Coca" and "Cola" are separated by a hyphen the eye moves across the logo fluidly.

\section{$\underline{\text { Closure }}$}

The principle of closure revolves around the idea of two or more shapes coming together and creating something new in the negative space. When this happens, the brain tends to notice the obvious structure of the shapes first and then catches on to the hidden shape over time. This execution has the strongest effect when the hidden shape communicates something powerful about the brand (La Rosa, 2019).

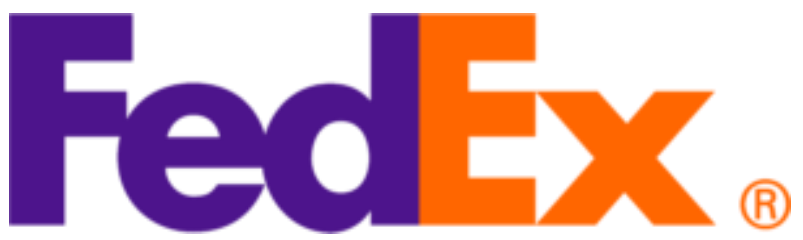

Figure 17: FedEx Logo (LaRosa, 2019) 
Volume 1 Number 1 Maiden Issue

The shipping company FedEx, employs closure very intelligently in their logo, as shown in Fig. 17. The vibrant colors and strong text of the FedEx logo, catches the eye at first glance and gives a strong impression which inspires trust and confidence. A closer look at the logo shows a shape hidden in plain sight. The letter $\mathrm{E}$ and the letter $\mathrm{X}$, in the logo, join together to create a rightward facing white arrow. Arrows would suggest speed, progress, and forwardthinking - an arguably, powerful shape to associate with a brand that is focused on crosscontinental package delivery.

\section{Proximity}

Proximity entails the relative distance between objects in relation to one another. When objects are close together they are assumed to be part of a group. On the other hand, when objects are displaced they are assumed to be alienated. The human brain tends to group objects as part of a collection regardless of their actual relation to one another.

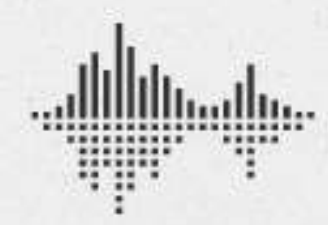

MYSTERY ISLANDS

Figure.18: Mystery Islands logo (Gert van Duinen)

In Fig. 18, the example of the logo Mystery Islands created by Gert van Duinen, reflects the principle of proximity. The designer used the proximity principle to create a shape of an island its reflection on the sea, the customer activity, dance music producer and recognizable as equalizer lines. This appears a perfect combination for the brand name: Mystery Islands.

\section{Figure and Ground}

Figure and ground principle holds that our perception tends to separate images into figure, or object, and ground, or background.

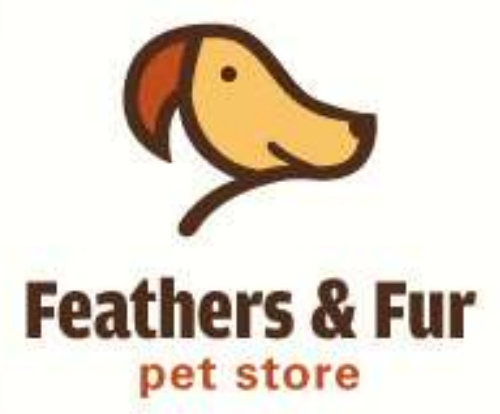

Figure 19: Feathers \& Fur Pet Store logo (Lumo) 
By following the Figure and Ground principle in the Feathers \& Fur Pet Store logo, the logo designer, Lumo, created a recognizable parrot on a branch and a dog's face in the logo to reflect the company's core business.

\section{WHY THE EMPHASIS ON GESTALT PRINCIPLES?}

Logo design is the result of creativity. Gestalt principles when used in tandem with the basic principles of design - visual proportion, colour dominance, elements organization, etc - offer the recipe for effective logo design (Kimbarovsky, 2020).

LaRosa (2019) opines that the biggest advantage of using Gestalt principles is that they give logos sticking power - they make the thing that represents businesses, fun, thoughtful, and memorable. That is why building the logo design of a brand around these principles is always desirable.

\section{THE PROBLEM}

Organizations often request for a logo design, unaware of the branding fundamentals and benefits. Many consider logos as mere symbols or signs, and truly undervalue the importance of professional logo designs, and the impact that bad logos can have on business (Cass, 2010). There is, also, the issue of some graphic artists not knowing the elements of good design or using mere raw talent in their creations (Hardy, 2009). Against this backdrop, it might be worthwhile to ask: what do graphic designers know and do with design principles like the Gestalt theory? Are they aware that the application of the Gestalt's principles of design can make for good professional logo designs? Do they actually apply these principles for their business Logo graphics or do they rely on instinctive raw talent to make their designs?

\section{AIM OF STUDY}

Based on the foregoing curiosity, the objective of the study was to examine the awareness and application of Gestalt's principles of design in business Logo graphics creation among Graphic artists in Awka urban area, Anambra State, Nigeria.

\section{RESEARCH QUESTIONS}

In order to aid the investigation of the research problem, the following questions were posed:

- What do logographic designers in Awka urban area know about the significance of good logos in business image-making?

- How aware are they of the Gestalt principles?

- Are they aware that these principles could aid the design of effective business logos?

- Do they apply these principles of design or 'raw' talent in creating logos for their clients?

\section{METHOD}

This study was designed as in-depth interview (IDI).The interview sought to elicit answers from respondents with regard to their awareness of the Gestalt principle and application of these in logo designs. 
Volume 1 Number 1 Maiden Issue

A purposeful decision was made to use Awka urban, Anambra State as a test case. The population for the study comprised six logo graphic designers in Awka urban business areas. There was apparently no data on the population of logo graphic designers in Anambra state, so the population centred on the available logographic designers who were evidently in business within three visibly major business areas in Awka urban namely, Unizik junction Eke-Awka, Amawbia, and Aroma junction. In-depth interviews were conducted with these people.

\section{RESULTS}

Data from these six IDIs were, analyzed and emerging themes interpreted in the light of the research questions.

The first IDI was conducted with a professional Graphic Artist / Designer in Amawbia area, this interviewee admitted to specialize in business logo designing apart from the general graphics. He knew what a logo was and the benefits of a good business logo. In his words "a good logo can attract people to your business and boost sales". However he sounded a bit hesitant when asked "do your clients decide their logo turnout or you do?" which gave an indication that he let his client's decision and choices prevail in his logo designs: he said "Hmm, I let them decide what they like oo!, afterall, they are the ones that end up using it not me, so I gladly give them what they want for my money".

In response to the question, "Do you work with design principles", the interviewee's face lightened with smiles. In his words, "well, every business has its own trade secrets, so does mine, I have principles and techniques, kind of like....my laid out presets!"

When asked what guides his creativity and what he considers when making client's business logos, the interviewee confidently said "as a graphic designer, I consider many things like what the client really wants, his taste as in class, what he deals in/services he renders, his company colour etc". Proceeding to the elements he considers when making logo designs he said, "I consider colours, fonts, symbols, balance, harmony aesthetics etc".

Narrowing down to the subject of the study, the interviewee was asked "Are you aware of the Gestalt principle of design?" He said "Yeah, we were taught that back in my school years, all about visual perception and unified whole abi [isn't it]?, I still remember that one".

When asked "So, do you apply this Gestalt principles on your client's logo design?" he smartly answered "Well, it depends on the class of the client, like I said most of these business people don't know all these details, they care about their banners with their business name's boldly written on them more than logos, they will prefer just an acronym of their business name as logos; logos are just to add a sense of completion for many of them so why bother for such a client? Unless we are talking corporate bodies that know what's up....then I can go back to my school fine arts notebooks, Gestalt principles and what have you."

The second IDI was with a roadside graphic artist also in Eke-Awka market area. This IDI reveals that this graphic artist was also into business-logo designing. On the benefits of a good business logo, he said, "A good business logo will always leave a symbol in the minds of your customers, so that each time they think of buying a particular product, they will quickly be confronted with the picture of your brand replaying in their minds, a good business logo is highly beneficial." 
On the question "who decides the logo turnout, you or your client?" The interviewee said he just plays according to his client's desires, since it is all about customer satisfaction at the end of the day.

The respondent was not emphatic about design principles, he strongly emphasized how his designs come from inspiration, in his words "I just go ahead and design the logo according to my inspiration at the time, I believe in the freedom of expression to achieve the best results, I do not believe in all these principles that could limit or cage my creativity."

The IDI revealed that this logo graphic artist relies solely on the client's instructions if any and adds a bit of his "inspirations" to perfect it. He is concerned with commercial appeal and he was not aware of the Gestalt principles of design and therefore do not apply it as He said "I don't know what that is, I have never heard about him or it"

The interviewee obviously was not aware of how to apply the gestalt principles to his logo creation and for that couldn't tell why it should be applied to his logographic designs.

The third IDI was with a professional graphic designer at Unizik Junction, this interviewee admitted to also offer the services of logographic designing. He also knew about the benefits of a good business logo. In his words, "a good business logo enhances brand preference among customers and ultimately promotes sales."

On who decides client's logo turnout, the respondent made a brilliant remark; "I usually don't pull a switch on my clients' requests but I diplomatically advise them according to the best of my work experience. Even when they won't listen I still find a way to show them what I mean by giving them varieties and letting them make a choice, that way everybody is happy, the client gets their dream business logo and I'd have my reputation and bragging rights intact".

Asked if he works with design principles, he responded "of course, I do work with basic design principles".

On what guides his creativity and his considerations when making a business logo he said "I get inspired by the nature of the client's business, it is easier when just an object, a tool or material can represent the entire business.eg, "an automobile servicing firm could be represented by a simple spanner or steering”.

Asked if he knew about the Gestalt Principles of design, He said "Yes I am aware of the Gestalt principles and I even apply them to my logo designs."

The interviewee also explained the reasons for making use of the Gestalt principles in his client's business logo design: "the Gestalt principles makes my work easier, rightful applications of any of the principles gives any logo a professional touch effortlessly".

The fourth IDI was with a graphic designer at Unizik Junction business area. This respondent was into logo designs. He knew what a logo was and the benefits of a good business logo. Regarding the benefits of a good logo", he said, "Generally, a good logo has a way of adding a touch of class to your business while a poorly done logo could devalue a brand".

On who makes the decision of the logo output, he responded, "Well, they say the customer is always right, but I won't fail to give my good guidance and professional touch finally". 
The respondent admitted to be working with basic design principles as his guideline; he also stated that he considers the basic design elements while working "e.g. shape, size, colour, balance and the rest of them".

On his knowledge about the Gestalt principles, he said, "Yes I do, if you are a true professional like me, you must have come across it one way or the other".

Asked if he applies them to his logo design his response was "Yes I do, though unconsciously. You see, often times, these principles play into my designs and they end up looking great but we don't always bear the Gestalt principle in mind while working. For me, it's all about the practical application and result".

On why he applies the Gestalt principles in his client's business logo designs, he said, "I apply these principles because overtime they've yielded awesome results for me. I'd advice my fellow graphic artists to read about it or at least know its application because it will enhance their productivity".

IDI number five was with a young female graphic artist in the Aroma business area. The interviewee showed she knew a lot about logo design and its benefits. She said, "I know good logos have the ability to give brands and businesses a memorable face, take a good look at LG, SONY,NIKE etc, and the way their logos represent them all over the world, it is a seal of pride, a mark of good quality and a symbol of what a brand stands for".

On "who decides the logo turnout," she said, "Well, for me, nobody should call the shots. It is better when ideas are combined, if the clients can do it, then why would they need my services? And if I go ahead and do logos my way, am I the person to use them? And that's why we all need to rub minds together for a great output".

Asked if she works with design principles, the respondent said, "Sure! There are rules and guidelines for virtually everything." For her, she considers "the clients' plan; they are the ones that need the logo, they are the ones that will use the logo, and so all I do is to make sure they end up loving what I give them at the end of the day".

In explaining the elements she focuses on when creating a business logo, she said, "lines, proportion, hue and value, colour balance and gradient and more".

The respondent's reply was "yes!" when asked if she was aware of the Gestalt principles. She continued; "we were taught that in school and they are helping me right now".

When asked if she applies the Gestalt principles and why she uses them in her client's business logo designs, she readily concluded "I apply them because as far as logo design is concerned, who can do without them? They are the backbones of all good logos out there including all the ones you know".

The sixth IDI was conducted with an amateur graphic artist at Aroma Junction business area.

The respondent quickly accepted that he offers the services of logo design, then went on to state confidently "isn't it that thing beside a company name, more like a signature?" On the benefits of a good logo, he said, "A good logo will benefit a brand because the owner would be happy with himself'. 
When asked if the logo turnout was his decision or the client's, he responded "well, here, all the client has to do is to bring his business name to us , trust, I always know what to do, once they pay me , they shouldn't worry".

Asked if he works with design principles, he answered, "Well, I work as I was taught". On what guides his creative flows and consideration when making client's business logos, he said, "shaa [really], it depends on the amount the person paid, you can't pay me one naira and expect a 5,000 naira job, no way!".

When asked the element he focuses on when designing a business logo, he said, "you know, everything nowadays is about swag [status] and 'pinging' [beautiful colours]".

About his knowledge of the Gestalt principles of logo design, he said, "I don't do that one. See my brother, all those ones are for those that have time, time is money, all these people (businessmen) don't even care so much about logo sef [even]! The banner is the main thing".

\section{ANALYSIS OF RESEARCH QUESTIONS}

The analyzed data was used to answer the four research questions posed in this study.

- Research question 1: What do logographic designers in Awka urban area know about the significance of good logos in business image-making?

In the First IDI, the respondent said "a good logo can attract people to your business and boost sales". In the Second IDI, the respondent said, "A good business logo will always leave a symbol in the minds of your customers, so that each time they think of buying a particular product, they will quickly be confronted with the picture of your brand replaying in their minds, a good business logo is highly beneficial". In the Third IDI, the interviewee said, "A good business logo enhances brand preference among customers and ultimately promotes sales". In the Fourth IDI, the respondent had this to say, "Generally, a good logo has a way of adding a touch of class to your business while a poorly done logo could devalue a brand". The respondent in the Fifth IDI said, "I know good logos have the ability to give brands and businesses a memorable face, take a good look at LG, SONY, NIKE etc, and the way their logos represent them all over the world, it is a seal of pride, a mark of good quality and a symbols of what a brand stands for". Finally the respondent from the Sixth IDI said, "A good logo will benefit a brand because the owner would be happy with himself".

From the six IDIs there is a suggestion that the respondents are aware of the significant benefits of good logos in business image-making.

\section{- Research question 2: How aware are they of the Gestalt principles?}

In the First IDI the respondent said "Yeah, we were taught that back in my school years, all about visual perception and unified whole abi [isn't it]?I still remember that one". In the Second IDI, the respondent was totally not aware of the Gestalt principle as he bluntly replied "I don't know what that is, I have never heard about him or it". In the Third IDI, the respondent said, "Yes I am aware of the Gestalt principles and I even apply them to my logo designs". The respondent in the Fourth IDI had this to say too, "Yes I do, if you are a true professional like me, you must have come across it one way or the other". In the Fifth IDI the respondent exclaimed "yes! We were taught that in school and they are helping me right 
now". Finally in the Sixth IDI, the respondent said, "I don't do that one. See my brother, all those ones are for those that have time, time is money, all these people (businessmen) don't even care so much about logo sef [proper]! The banner is the main thing".

Excerpts from the Six IDIs for this study show that only two respondents (the Second IDI and the Sixth IDI) were not aware of the Gestalt principles of design.

- Research question 3: Are they aware that these principles could aid the design of effective business logos?

Excerpts from the foregoing analysis of the research question 3, shows evidence that the three respondents (Third, Fourth and Fifth IDIs) who applied the Gestalt principles were also aware of how they could aid them create effective business logos. Therefore, their responses sounded like words of advice.

In the Third IDI, the respondent replied, "...rightful application of any of the principles gives any logo a professional touch effortlessly". In the Fourth IDI, the respondent knew certainly and for this he advised his peers, "...I'd advice my fellow graphic artists to read about it or at least know its application because it will enhance their productivity". The respondent in the Fifth IDI said, "...They are the backbones of all good logos out there including all the ones you know".

- Research question 4: Do they apply these principles of design or 'raw' talent in creating Logos for their clients?

In the First IDI, the respondent said "Well, it depends on the class of the client. Like I said, most of these business people don't know all these details, they care about their banners with their business name's boldly written on them more than logos, they will prefer just an acronym of their business name as logos, logos are just to add a sense of completion for many of them, so why bother such a client, unless we are talking about corporate bodies that know what's up....then I can go back to my school fine arts-notebooks, Gestalt principles and what have you".

In the Second IDI, The interviewee obviously was not aware of how to apply the gestalt principles to his logo creation and for that couldn't tell why it should be applied to his logographic designs.

In the Third IDI, the respondent replied, "the Gestalt principle makes my work easier, rightful applications of any of the principles gives any logo a professional touch effortlessly".

The respondent in the Fourth IDI added a piece of advice; "I apply these principles because overtime they've yielded awesome results for me; I'd advice my fellow graphic artists to read about it or at least know its application because it will enhance their productivity". In the

Fifth IDI the respondent said, "I apply them because as far as logo design is concerned, who can do without them? They are the backbones of all good logos out there including all the ones you know".

The respondent in the Sixth IDI was rather ignorant of the Gestalt principles and did not see the need to apply them in creating logos for his clients. 


\section{CONCLUSION}

This study sought to establish awareness and application of the Gestalt principles of design in logo graphic communication among graphic designers in Awka urban areas.

The major findings of this study would suggest that the respondents were majorly aware of the gestalt principles but some did not end up applying them, and even when they do, they applied them wrongly. This leads to the conclusion that there is likelihood that the logographic designers in Awka urban, in the main, do not rightfully apply the gestalt principles of design, for effective logographic communication; obviously neglecting a handy tool in the professional design of logos.

\section{REFERENCES}

Bradley, S. (2014). Design principles: Visual perception and the principle of Gestalt.

Retrieved from https://www.smashingmagazine.com/2014/03/design-principles-visualperception-and-the-principles-of-gestalt/

Carrie, C. (2020). Importance of logo. Retrieved from https://www.carriekuehn.com/importance-of-a-logo

Cass, J. (2010). Branding, identity and logos explained. Retrieved from https://justcreative.com/2010/04/06/branding-identity-logo-design-explained/

Hardy, G. (2009). 10 common mistakes in logo design. Retrieved from https://www.smashingmagazine.com/2009/06/10-common-mistakes-in-logo-design/

Hergenhahn, B.R. (2009). An Introduction to history of psychology (6 $6^{\text {th }}$ ed.). Belmont: Wadsworth.

Kimbarovsky, R. (2020). How to create a unique and memorable brand identity in 2020. Retrieved from https://www.crowdspring.com/blog/brand-identity/

LaRosa, C. (2019). How can the Gestalt Theory make your logo stand out? Retrieved from https://phoscreative.com/can-gestalt-theory-make-logo-stand/

Mertes, A. (2020). History of logo design. Retrieved from https://www.qualitylogoproducts.com/promo-university/history-of-logo-design.htm

Szwemin, A (2015). Visual Literacy. Retrieved from https://annaszwemin.wordpress.com/visual-literacy/the-use-of-white-space-ingraphic-design/gestalt-principles/ 